\title{
La contribución del aprendizaje de los procesos creativos en la conciencia política de los estudiantes.
}

Trabajar frente a los prejuicios y las "ideas" en el aprendizaje de los procesos creativos como base para una educación democrática que contribuye en el desarrollo de la conciencia política de los estudiantes.

\section{Contribution of the creative process learning to the political awareness of students.}

Working against prejudices and "ideas" in the creative process learning as a basis for a democratic education that contributes to the development of the political awareness of students.

\section{Psegiannaki, Katerina ${ }^{1}$; García Triviño, Francisco ${ }^{2}$}

1. Universidad Camilo José Cela, Escuela de Arquitectura y Tecnología, Madrid, España, katerina@hipo-tesis.eu

2. Universidad Camilo José Cela, Escuela de Arquitectura y Tecnología, Madrid, España, francisco@hipo-tesis.eu

\begin{abstract}
Resumen
La principal hipótesis del presente artículo es que el aprendizaje de los procesos creativos puede contribuir no solamente en el desarrollo de las aptitudes y destrezas artísticas sino también en el desarrollo de la concienci a política de los estudiantes.

Para desarrollar esta hipótesis de partida se explora qué es la educación, cuál es su relación con la democracia, cuáles han sido los modelos educativos más influyentes y cuál es o puede ser su vinculación con la actitud polít ica de los ciudadanos. De forma más concreta se acude a la argumentación que establece Rancière entre arte y política para identificar campos de trabajo en el aprendizaje de los procesos creativos. Se analiza brevemente para este tipo de aprendizaje; la concienciación de los prejuicios y el cuestionamiento de las ideas, pues tienen una fuerte vinculación con la política.

Por último, se propone el diálogo analítico como herramienta con la que trabajar en estos campos, capaz de reconstruir un espacio de disenso político y artístico.
\end{abstract}

Palabras clave: política, educación, procesos creativos, prejuicios, ideas.

\begin{abstract}
The main hypothesis of this paper is that creative processes' learning can contribute not only to develop the arti stic abilities and skills but also in the political consciousness of students.

To elaborate this hypothesis the definition of education and its relation with democracy is explored, together with the most influential educational models and their possible link to the political behavior of citizens. More specifically we turn to the argument that was developed by Rancière creating relation between art and politics to identify different areas of work in learning creative processes. This type of learning is being discussed briefly; raising awar eness regarding prejudices and questioning ideas, both critical situations in political behavior of citizens.

Finally, the analytic dialogue is proposed as a tool to work in these areas, able to reconstruct a political and artistic dissensus of space.
\end{abstract}

Key words: politics, education, creative processes, prejudices, ideas. 


\section{Introducción: Estado de la cuestión}

En la mayoría de las aportaciones que uno puede encontrar sobre educación, ésta se relaciona con la democracia como la forma más acorde para constituir la conciencia política de los ciudadanos de una sociedad. En este artíc ulo se quiere reflexionar sobre la posibilidad de que los procesos creativos en la educación pueden también contribuir con especial interés en esta dirección.

Con "procesos creativos en la educación" nos referiremos a la "praxis" creadora, y la reflexión previa y posterior que ella supone, especialmente en los ámbitos educativos.

Con la palabra "política" se hace referencia a la conciencia de los estudiantes como ciudadanos, es decir a la "a ctividad del ciudadano cuando interviene en los asuntos públicos con su opinión, con su voto, o de cualquier otro modo." (RAE)

La urgencia de reflexionar sobre educación, democracia, ciudadanía y conciencia política es debida a la situación de crisis política y de valores en la que estamos inmersos. La vinculación de ésta reflexión con el ámbito de trabajo de cada uno, en nuestro caso la educación de los procesos creativos, se considera necesaria ya que el ciudadano se hace en su hacer y la conciencia de éste se desarrolla en su día a día.

Cuando una clase se transforma en una incubadora de conciencias (políticas o ciudadanas) se puede apreciar mejor el sentimiento de igualdad entre sus integrantes. Nadie es más ciudadano que otro. El discurso ya no es unilateral, desde el pódium del maestro "conocedor" de la materia impartida, sino que está dirigido des de todos y hacia todos de forma dialógica. Los estudiantes y maestros se muestran iguales frente a las reflexiones compart idas y se aprende de todos y entre todos. La praxis creadora de los integrantes del grupo contribuye en la mejor compresión de los temas tratados ya que cada integrante del diálogo seguramente habrá tenido una experiencia propia de donde puede trasladar reflexiones, dificultades, pensamientos y sentimientos propios, así podrá compartirlos y reflexionar sobre ellos.

\section{2. ¿Qué es la educación?}

En el diccionario de las Ciencias de la Educación (Sánchez Cerezo, et al. 1994, p.475) se nos informa del origen de la palabra Educación. Pues esta proviene, fonética y morfológicamente, de educare que significa "conducir", "guiar", "orientar"; pero semánticamente recoge la versión de educere que significa "hacer salir", "extraer", "dar a luz". Según el autor de la entrada estas dos significaciones han permitido la existencia de dos modelos conceptuales básicos en educación. El primero, es un modelo "directivo" o de intervención y el segundo es un modelo de "extracción" o desarrollo. También hay un tercer modelo ecléctico que asume y admite ambas instancias, dirección y desarrollo.

En la misma línea que estas definiciones, que aunque lingüísticas cobran significado de modelos conceptuales educativos, se han movido muchas de las posturas de los teóricos de la educación, que consisten en la pugna entre ser social que es lo que se quiere conseguir bajo la dirección externa de los individuos, y el ser individual que apuesta en lo singular que cada persona posee y se desarrolla desde dentro según el modelo de extracción. Como lo define Emile Durkheim:

En cada uno de nosotros existen dos seres que aun cuando inseparables a no ser por abstracción no dejan de ser distintos. El uno está constituido por todos los estados mentales que no se refieren más que a nosotros mismos y a los acontecimientos de nuestra vida privada: es lo que se podía denominar el "ser individual". El otro es un sistema de ideas, de sentimientos y de costumbres que expresan en nosotros, no nuestra personalidad sino el grupo o los grupos diferentes en los que estamos integrados; tales son las creencias religiosas, las opiniones y las practicas morales las tradiciones nacionales o profesionales, las opiniones colectivas de todo tipo. Su conjunto constituye el "ser social". (1975, p.54)

Esta teorización del ser humano ha cobrado sentido en los diferentes modelos educativos que o se colocan a favor del primer modelo educativo o a favor del segundo con sus respectivas maneras. También hay los que han criticado esta tendencia dualista de tener que pensar en forma de oposiciones extremas. John Dewey, por eje mplo, considerado padre de la educación progresista, se ha opuesto a estas divisiones radicales de "o lo uno o lo otro" que no reconocen posibilidades intermedias;

...la historia de la pedagogía se caracteriza por la oposición entre la idea de que la educación es desarrollo desde dentro y la de que es formación desde fuera; la de que está basada en los dotes naturales y la de que la edu-

La contribución del aprendizaje de los procesos creativos en la conciencia política de los estudiantes.

Psegiannaki, Katerina; García Triviño, Francisco. D.O.I. 10.14198/i2.2016.5.02 
cación es un proceso para vencer las inclinaciones naturales para sustituirlas por hábitos adquiridos bajo la presión externa (Dewey, 2004, p.65).

Es en este caso es cuando surge la tercera vía que es más ecléctica y más crítica con los radicalismos de las anteriores.

\section{El modelo directivo}

El primer modelo entonces según el diccionario de las ciencias de la educación - el directivo - se asocia al tema de la socialización es decir la necesidad de desarrollo del ser social que en cierto sentido refleja el contex to s ociocultural de cada lugar y época. Este modelo ha sido apoyado por tendencias tradicionales de la educación donde el conocimiento y las reglas de conducta de la sociedad, están considerados como lo más importante para la convivencia del grupo, y lo más valioso para la educación de los individuos.

En cada sociedad, se labra un cierto ideal del hombre desde el punto de vista intelectual, físico y moral. Ese Ideal es, en cierta medida, el mismo para todos los ciudadanos de un país; aunque, a partir de un determinado punto, se diferencia según los ámbitos particulares que toda sociedad alberga en su seno. (Durkheim, 1975, .p52)

Una de las cuestiones importantes para que el modelo "ideal" pueda ser definido tiene que ver con los fines de la educación. Tales fines son una cuestión constante y uno de los principales temas de la "filosofía de la educación". Ferrater Mora (1965) en su diccionario de filosofía en la entrada "Educación", comenta que estos fines no pueden ser ideales neutros ya que están fuertemente condicionados por ciertos supuestos de acuerdo con los que opere el filósofo, que aunque sus observaciones y anotaciones sobre los temas que trata se hace desde una mirada exterior, es cierto que por mucho que lo intenta no puede separarse de su época. Estos supuestos son convicciones previas - políticas y religiosas - ciertas ideas básicas - cómo la idea acerca del ser humano y su puesto en el mundo - y también creencias de una cultura determinada o de un período histórico determinado (Mora, 1965, p.499).

La educación por lo tanto es una "realidad histórica", no "natural", producida por el ser humano y vinculada al contexto sociocultural y político de cada momento. Todo sistema educativo, al plantearse unos "fines" y un "ser ideal" para alcanzar, se encuentra inevitablemente influenciado por su época y refleja ciertos patrones referenciales socioculturales de esta (Sánchez Cerezo, et al. 1994, p.475).

No obstante, lo contrario sería imposible; es decir, no podemos hablar de una educación no influenciada por la sociedad y la época en la que se desarrolla, ya que esta nace y ocurre en sociedad, entre seres humanos que aunque individualmente son capaces de aprender por su experiencia en el mundo lo que es específicamente humanizador en sus procesos educativos es la vinculación intersubjetiva entre sus conciencias (Savater, 2003, p.30) que sólo ocurre por vivir y estar juntos en el mundo. La vida humana consiste en habitar un mundo en el que las cosas no sólo son sino también significan, y este significado:

...es lo que uno no puede inventar, adquirir ni sostener en aislamiento sino que depende de la mente de los otros... La verdadera educación no sólo consiste en enseñar a pens ar sino también en aprender a pensar sobre lo que se piensa... (Savater, 2003, p.30).

La educación entonces no consiste sólo en conocer el mundo y las cosas que nos rodean sino en aprender ta mbién a pensar sobre los significados que los seres humanos han ido generando y atribuyendo a las cosas, y las interpretaciones del mundo que han ido construyendo. Este hecho es obligatoriamente social y político, y contribuye no solamente en el desarrollo del "ser social" sino también del "ser individual". Pensar sobre el pensamiento generado por los seres humanos es también luchar por que este pensamiento exista y siga produciéndose libremente.

Como observa Durkheim (1975, p.57) en las sociedades más simples y primitivas donde la educación se basaba en la tradición y el mito, el pensamiento y el libre albedrío resultaban inútiles e incluso peligrosos puesto que eran una amenaza latente para la tradición En las sociedades más complejas donde la educación apuesta por el pe nsamiento libre de sus integrantes es donde puede llegar a nacer la liberación del mito como explicación de las cosas (Lledó, 2009, p.56). En una sociedad avanzada y en sus procesos políticos y de ciudadanía "no se trata solo de poder decir, de poder expresarse sino de poder pensar, de aprender a saber pensar para, efectivamente, tener algo que decir" (Lledó, 2009, p.56). Y este algo aporta a ambos seres, individual y social, que aunque distintos son inseparables y dependientes en su desarrollo.

En este sentido lo que se puede concluir es que efectivamente una educación desvinculada del medio social y las metas que este nos fija sería una utopía ya que la educación es un hecho, una invención e intervención humana, 
necesariamente social. Sin embargo como la sociedad es un "ente" que también cambia, avanza y se desarrolla a lo largo del tiempo de manera incontrolada, tampoco la tendencia tradicional de fijar ideas y materias de estudios estándares y atadas en un pasado "idealizado", y dirigir los individuos para que las adquieran mediante presión externa, deja de ser un comportamiento utópico que no ayuda para tratar los sucesos del presente y del futuro (Dewey, 2004, p.70).

En esta dirección, y bajo un continuo replanteo de los fines e ideales de la educación en una sociedad continuamente cambiante, puede contribuir la educación en los procesos creativos y el pensamiento que a través de ella se cultiva.

\section{El modelo de extracción}

El segundo modelo que surge del análisis lingüístico de la palabra educación cuando esta cobra significado semántico, es el de extracción y se asocia con lo que Durkheim denomina desarrollo del "ser individual". Al ser un modelo que apuesta más por la diferencia y el desarrollo, antes que a los principios tradicionales, ha sido adopt ada por modelos educativos progresistas que ven en cada individuo un mundo potencial nuevo que no debe ser reprimido por la sociedad sino adecuadamente extraído para poder aportar en ella.

Jean Jacques Rousseau al que se le considera el padre de este modelo educativo, desarrollado en su libro "Emilio o Sobre la Educación". El modelo de aprendizaje que Rousseau plantea para Emilio se opone a las formas del desarrollo "corrompidas" y "artificiales" que son resultado de la sociedad y apuesta por dejarle aprender en un estado "natural". La educación de Emilio es individual, experiencial y le mantiene lejos y libre de las influencias corruptas de la sociedad (Jay, 2009, p.18).

En una época bastante más reciente este modelo educativo se empieza a desarrollar dentro de las escuelas por parte de educadores que se definen como progresistas. Eliot Eisner presenta la visión de quienes estaban influidos por las teorías progresistas y estaban interesados en utilizar el arte como un medio que ofreciera a los niños la oportunidad de autoexpresión creativa (Eisner, 2009, p.41). El niño debía ser libre para desarrollarse de forma natural, y el profesor debía funcionar como guía y no como amo. El profesor no tenía que enseñar, sino posibilitar la creatividad del niño ofreciéndole un entorno estimulante y los medios artísticos nec esarios. Las ideas progresis tas se orientaban hacía un tipo de Neorousseaunismo que defendía el mantenimiento de la ingenuidad del niño en nombre de la visión pura. La función del profesor sería mantener el vigor y la espontaneidad del niño evitando su contacto con los productos de la especie humana. Esta concepción del desarrollo infantil, y del papel del profesor, se basa en la idea de que el niño se desarrolla mejor desde dentro hacia fuera que desde fuera hacia dentro (Eisner, 2009, pp.45, 46).

Sin embargo Dewey, que como dijimos se oponía a todo tipo de dualismos radicales extremos, no dudaba en criticar que la postura progresista era una mala interpretación de la teoría experimental de la educación - de la que él fue pionero. Lo que observó era un exceso de permisividad en nombre de la libertad y como dice:

No es excesivo afirmar que una filosofía de la educación que pretende basarse en la idea de la libertad pueda llegar a ser tan dogmática como lo era la educación tradicional frente a la que reacciona. Pues toda teoría y serie de prácticas son dogmáticas cuando no se basan sobre el examen crítico de sus propios principios básicos. (Dewey, 2004, p.69)

Hannah Arendt que también establece una crítica frente a estas tendencias educativas, la educación moderna, en la medida que aspira a establecer un mundo de niños, destruye las condiciones necesarias y vitales para el desarrollo y el crecimiento.

Los educadores representan para el joven un mundo cuya responsabilidad asumen, aunque ellos no son los que Io hicieron y aunque, abierta o encubiertamente preferirían que ese mundo fuera distinto. Esta responsabilidad no se impuso de modo arbitrario a los educadores, sino que está implícita en el hecho de que los adultos introducen a los jóvenes en un mundo que cambia sin cesar... (Arendt, 1996, p.201)

Independientemente de estas posturas y las críticas que sobre ellas se establecen, la necesidad de desarrollo del ser humano es un hecho, y esto no puede ser motivado sólo desde fuera, ya que la implicación del propio individuo, su desarrollo desde dentro, es un supuesto necesario que inevitablemente se relaciona con la dimensión política y social de los individuos.

Según lo han expresado varios pensadores, el ser humano no nace completo, sino con una potencialidad latente que será desarrollada a lo largo de su vida.

La contribución del aprendizaje de los procesos creativos en la conciencia política de los estudiantes.

Psegiannaki, Katerina; García Triviño, Francisco. D.O.I. 10.14198/i2.2016.5.02 
"Mientras que los demás seres vivos nacen ya siendo lo que definitivamente son, lo que irremediablemente van a ser......, los humanos nacemos para la humanidad. Nuestra humanidad biológica necesita una confirmación posterior, algo así como un segundo nacimiento en el que por medio de nuestro propio esfuerzo y de la relación con otros humanos se confirme definitivamente el primero." (Savater, 2003, p.22)

Este proceso humanizador no es un proceso que tiene fin, sino puede durar a lo largo de la vida. "La educación como proceso temporal se identifica con la vida, porque el ser humano está y es permanentemente inacabado y su construcción le ocupa su tiempo vital" (Sánchez Cerezo, et al. 1994, p.475). Según este acercamiento la educación debe ser un proceso activo que implica el propio sujeto que se educa en todos los momentos de su vida, ya que sin su implicación sería imposible ser educado. El ser humano "se construye" por su actividad ( $\underline{\text { Sánchez }}$ Cerezo, et al. 1994, p.475), y esta actividad tiene que obtener del espacio-tiempo suficiente para des envolverse y permitir el desarrollo de la potencialidad que cada individuo posee.

La puesta en acción de cada persona es la que genera el proceso educativo y el desarrollo necesario para la plenitud de su ser individual. La acción, es un factor significativo en la vida humana y su desarrollo y es también uno de los factores que relacionan el ser social con el ser individual. Para Arendt la esfera política surge de la acción, del tener que actuar juntos, de tener que compartir palabras y actos (Bárcenas 2006, p.187). La acción y el habla son supuestos de la pluralidad humana que tiene un doble carácter de igualdad y distinción. Los seres humanos al no ser ni totalmente distintos ni al contrario, totalmente iguales, necesitan de la acción y del habla para hacerse entender el uno al otro. La acción es la que hace aparecer en el mundo lo inédito cosa que podemos decir que ocurre en un proceso educativo activo, donde cada persona consigue desarrollar la parte singular de su personal idad y esta parte singular, si consigue ser debidamente desarrollada, puede aportar en lo social y lo colectivo.

\section{El modelo ecléctico}

El tercer modelo, el ecléctico, se puede vincular con lo que Arendt asigna cuando en su ensayo "La Crisis de la Educación" se refiere a una necesidad conservadora en la educación, que pueda proteger el mundo de los nuevos que vienen, y los nuevos ( $y$ todo lo inédito que el ser nuevo implica) del mundo existente.

Me parece que el conservadurismo, en el sentido de la conservación, es la esencia de la actividad educativa, cuya tarea siempre es la de mimar y proteger algo: el niño ante el mundo; el mundo ante el niño; a lo nuevo ante a lo viejo; a lo viejo ante a lo nuevo. (Arendt, 1996, p.202)

Rousseau aunque más a menudo se vincula con el modelo de "extracción" adoptado por los progresistas, en "EI Contrato Social" reflexionó sobre este conflicto que surge entre sociedad e individuo, y sus observaciones son bastante pertinentes para un modelo más ecléctico y equilibrado que responda a la necesidad de una socializ ación. Bajo su teoría, la historia de la civilización consiste por una parte en un progreso innegable de las facultades y conocimientos de los humanos, y por otra en una perdida continua de libertad e igualdad naturales que se debe a su condición política. La educación se enfrenta a esta contradicción, entre la integración social del individuo, ya que no hay vida plenamente humana en solitario, y el tener que evitar que el individuo, que no tiene otro remedio que vivir en sociedad, sea modelado y absorbido por completo por una sociedad que ha degenerado por las desigualdades y los conflictos sociales (Sotelo, 1996).

Herbert Read (2010, p.31) hace también una interpretación bastante acertada de este conflicto entre individuo y sociedad desplazando el fin en una cosa intermedia. Apoya la opinión que la educación tiene como finalidad fomentar lo que cada ser humano posee de individual ayudando el individuo a llegar a ser el que realmente es, pero también reconoce que esta singularidad carece de valor práctico en el aislamiento por lo tanto la educación tiene que apostar por armonizar esta individualidad con la unidad orgánica del grupo social.

En la misma línea, Durkheim (1975, p.52), no sólo habla por la homogeneización de los comportamientos acept ados en una sociedad determinada sino también por la necesidad de diversificación que ayuda resaltar lo singular de cada individuo, que es necesario para que toda sociedad pueda avanzar

Por esas razones y en búsqueda de este equilibrio entre individuos y unidad social parece ser que según Rousseau la meta de la política, y de la educación, debería ser:

...encontrar una forma de asociación que defienda a la persona y los bienes de cada miembro con la fuerza colectiva de todos, y en virtud del cual, cada individuo, mientras se une con los demás obedece a nadie más que a símismo, y sigue siendo libre como antes. Este es el problema fundamental al que el contrato social tiene la solución. (Roberts \& Sutch, 2006, p.98) 
Como observa Ignacio Sotelo:

...en la intención fundamental del Contrato Social parece ser que la democracia, en la que se reconcilian la libertad y la igualdad, ambas constitutivas de lo humano, es la única forma de gobierno propia de seres humanos libres e iguales. (1996)

¿Cómo sería entonces una pedagogía que se plantea desde éste horizonte democrático?

\section{Educación y democracia}

Ignacio Sotelo (1996) plantea la diferencia entre instrucción socialización y educación. Mientras que la primera se ocupa de la formación práctica destinada al trabajo la segunda se centra en el aprendizaje de los principios gen eralmente aceptados de la sociedad y la tercera apuesta por el desarrollo de seres humanos libres e iguales. Mediante el examen de las posturas de Rousseau, Sotelo reconoce tres puntos muy importantes que apuestan hacia esta pedagogía democrática.

Lo primero y más importante en esta pedagogía, es que no puede ser un proceso impuesto desde fuera. Al contrario consistirá en la eliminación de los factores externos que impiden a cada uno de nosotros llegar a ser el que realmente es. (Sotelo, 1996)

En segundo lugar tal pedagogía respondería a la necesidad de "protegernos" de la socialización, o al menos de ciertos aspectos de esta, especialmente los que puedan funcionar de forma coactiva e impedir el desarrollo libre de las personas.

Por último para que la educación supere a la socialización, importa también, no sólo diferenciar educación de in strucción sino poner todo el énfasis en la primacía de la primera. Rousseau es enemigo de toda instrucción retórica y al contrario está interesado no en que aprendamos los nombres de las cosas sino en que podamos llegar a ellas cuestionándolas.

No se trataría de enseñar los saberes sociales, clasificados y ordenados, sino de aprender a pensar por sí mismo: sólo el que piensa por sí mismo puede llegar a ser uno mismo. La enseñanza para la libertad, desde la libertad, supone una educación crítica, consigo mismo y con el mundo que le rodea, única forma de crear el tipo de ciudadano que necesita la democracia (Sotelo, 1996).

\section{Relación entre política y educación}

La política, como la educación, es también resultado y condición, de la vida común entre los seres humanos. Ambas las define una relación de retroalimentación; la educación apuesta por formar el ciudadano cuya acción polít ica sea democrática y la política apuesta por proporcionar a sus ciudadanos una educación que es capaz de crear el tipo de ciudadano que necesita la democracia.

La política según Platón nace de la negación de la autarquía y de la necesidad de dar y prestar ayuda. Cómo el mismo dice en la República ninguno de nosotros se basta a sí mismo - estamos necesitados de muchas cosas. La política es pues, según Platón, búsqueda de equilibrio, motor de solidaridad, problemática y apasionante sociabilidad (Lledó, 2009, p.54). Lledó observa que la generosidad por muy irreal que pudiera parecer, se anunció ya en los primeros escritos políticos de lo que se suele denominar cultura occidental. Observa que en la república de Platón se hablaba de los guardianes o protectores de la ciudad, los políticos, que, según comenta, eran felices porque no podían poseer bienes materiales.

Ni manejar oro ni plata [...] porque si buscan el dinero se convertirán no en protectores y amigos de sus conciudadanos, sino en odiosos déspotas. Pasarán la vida entera aborreciendo y siendo aborrecidos, conspirando y siendo objeto de conspiraciones, temiendo, en fin, mucho más y con más frecuencia a los enemigos de dentro que a los de fuera. Correrán así en derechura al abismo y se hundirán ellos y, con ellos, la ciudad y sus ciudadanos. (República, III, 417a-b)

Este extracto de la república es interesante en la medida que plantea el giro radical en la cultura griega en la que, como observa Lledó, aparece una variante revolucionaria;

...la felicidad ya no consiste en tener más sino en ser más. Y este ser más abre el espacio de la intimidad, la construcción de un ser dentro de nosotros mismos, cuya posesión y gozo son infinitamente más reales que la posesión de cosas. (Lledó, 2009. pp.54,55).

La contribución del aprendizaje de los procesos creativos en la conciencia política de los estudiantes.

Psegiannaki, Katerina; García Triviño, Francisco. D.O.I. 10.14198/i2.2016.5.02 
Este ideal de "ser más" frente al "tener más" abrió el camino hacia la "paideia". Ser más significa implicarse act ivamente en los procesos educativos que proporciona la "polis", y participar en estos procesos educativos significa querer ser ciudadano de ella y querer participar en la política.

En un análisis parecido, esta vez desde el punto de vista de la política, Rancière ve en ella la posibilidad de una "redistribución de lo sensible". Plantea algunas interpretaciones acerca de cómo la política está comprendida en los textos de Platón y Aristóteles y como tales son entendidas e interpretadas en la actualidad.

Para acercarse a esos asuntos recurre al libro I de la Política de Aristóteles donde se comenta que el ser humano, es político porque posee el lenguaje que pone en común lo justo y lo injusto, mientras que el animal solo tiene el grito para expresar placer o sufrimiento. Sin embargo, observa que la cuestión reside en saber quien posee el lenguaje y quien solamente el grito.

El rechazo a considerar a determinadas categorías de personas como individuos políticos ha tenido que ver siempre con la negativa a escuchar los sonidos que salían de sus bocas como algo inteligible. O bien con la constatación de su imposibilidad material para ocupar el espacio-tiempo de los asuntos políticos. (Rancière, 2005, p.18)

En la Republica de Platón los artesanos no tienen tiempo para estar en otro lugar que en su trabajo, y por supuesto este otro lugar donde no pueden estar es la asamblea del pueblo. Son por lo tanto la falta de tiempo, la impos ibilidad de estar en ciertos lugares y de ser escuchados o visibles otros tipos de prohibiciones naturales, inscritas en las formas de la experiencia sensible (Rancière, 2005, p.18). Pero, como sigue Rancière en su ensayo,

...la política sobreviene cuando aquellos que «no tienen» tiempo se toman ese tiempo necesario para erigirse en habitantes de un espacio común y para demostrar que su boca emite perfectamente un lenguaje que habla de cosas comunes y no solamente un grito que denota sufrimiento. (Rancière, 2005, p.18)

Esta distribución de lugares, de tiempos, de quienes poseen el lenguaje y quienes el grito, quienes son visibles y quienes no, en el espacio común, es lo que Rancière (2005, p.19) denomina como "división de lo sensible". La política consiste en reconfigurar esta división, introducir sujetos y objetos nuevos, hacer visible lo invisible, escuchar como seres dotados de la palabra a aquellos que no eran considerados más que como animales ruidosos.

Educación y política constituyen un vínculo imprescindible para los ideales de la democracia. El reconocimiento de que la cultura se creaba entre los entramados de la Polis y de que la convivencia era algo más que la manifestación de los intereses del individuo, trajo consigo el fundamento principal de la convivencia, la Paideia, la educación, exigencia ineludible de la democracia (Lledó, 2009, p.55). La política por otra parte, viene a cuestionar y replantear, la "división de lo sensible" que el orden establecido proporciona. Y como éste orden a veces se reproduce en los modelos educativos de cada época, lo político - la toma de conciencia y de palabra del que no la poseía - se alza para alterar tal orden y establecerlo de nuevo, en un proceso incesante.

¿Cómo entonces los procesos creativos en la educación pueden involucrar al ciudadano en la política?

Según Rancière (2005, p19) "la política del arte consiste en interrumpir las coordenadas normales de la experiencia sensorial" establecida. Esta interrupción, que traemos del arte al aprendizaje de procesos creativos, tiene el fin de replantear, recolocar al ciudadano frente al mundo a partir del disenso, la irrupción del ciudadano en la política de lo establecido, acordado, asentado. No queriendo decir con ello que todo proceso creativo tenga que i mplicar una práctica política, ni toda práctica política necesite de un proceso creativo de reconfiguración de lo est ablecido. Sino que existe una relación de implicación, donde el ciudadano, el aprendiz, se ve forzado a tomar parte en la reconfiguración relacional, política, en el arte.

El disenso en los procesos creativos puede ser el medio para concienciarse de nuestros prejuicios y encontrar la alternativa a la búsqueda de ideas que coacciona nuestros procesos. Estos dos campos de trabajo en el aprendizaje pueden definir entornos de interrupción de las coordenadas normales de la experiencia sensorial.

\section{Trabajar frente a los prejuicios}

El disenso tomaría lugar y la división de lo sensible se replantearía, si primeramente se conciencian y se cuestionan nuestros prejuicios, que al mantener y reproducir las lógicas existentes, bloquean tanto los procesos creativos como aquellos procesos políticos que apuntan al cambio. Tratar con ellos y aprender a reconocerlos para dejar que el disenso tome lugar, constituiría un proceso educativo.

Según Hannah Arendt, la desaparición de prejuicios sólo significa que ya no tenemos las respuestas en las que

La contribución del aprendizaje de los procesos creativos en la conciencia política de los estudiantes.

Psegiannaki, Katerina; García Triviño, Francisco. D.O.I. 10.14198/i2.2016.5.02 
habitualmente nos fundábamos, sin ni siquiera comprender que en su origen eran respuestas a preguntas. Es muy común responder a nuevos problemas, con respuestas antiguas, pero son principalmente las situaciones de crisis las que nos obligan volver a plantearnos preguntas y nos exigen juicios directos. (Arendt, 1996, p. 186).

En los procesos creativos para que el disenso tome lugar es necesario alejarse del pensamiento cotidiano que arrastra muchos prejuicios, es importante preguntarse continuamente del porqué de las cosas es decir ponerlas en "crisis" aunque no estén por sí mismas. Agnes Heller (1987, pp.293, 294) identifica como "pragmáticos" el pensamiento y comportamiento cotidianos porque normalmente prescinden del porqué de la función de las cosas reaccionando a estas tal y como son sin cuestionar su génesis. Este comportamiento por parte es lógico y no es un defecto en la vida cotidiana ya que sería imposible adoptar una actitud teorética hacia todo objeto de uso. P ero fuera del radio de la acción, de la vida y del pensamiento cotidiano, formular preguntas acerca de la génesis y del porqué de las cosas es necesario para someter en discusión o refutar ciertas costumbres que se han cristal izado en convenciones, clichés y prejuicios y ser capaces de ampliar y actualizar nuestro conocimiento acerca de lo real.

En los procesos creativos es también importante preguntarse no sólo el porqué de las cosas que nos rodea sino también el porqué de nuestras respuestas que a veces son automáticas y responden a los problemas planteados con convenciones y prejuicios. Como vimos también en el desarrollo de los modelos educativos, toda teoría y toda práctica, toda respuesta segura a cualquier pregunta, pueden ser igual de dogmáticas cuando no se bas an al examen crítico de sus propios principios básicos. En este sentido, arte, política y educación siempre que apuestan por un futuro mejorable deben ser capaces de concienciar y superar los prejuicios que las rigen. Y c $0-$ mo se habla de personas y no de conceptos, es la educación desde las personas y hacia las personas la que puede contribuir a este fin, y especialmente es la educación de los procesos creativos la que tiene esta facilidad, ya que suele trabajar con desubicar la realidad y "ficcionarla" para pensarla de nuevo. Esto es también un comportamiento necesariamente político, o un comportamiento que necesariamente debe tomar lugar en la política. Entrenarlo en los procesos creativos puede hacer que este sea más operativo.

\section{Trabajar frente a la búsqueda de ideas}

Otra cuestión con la que nos ponemos escépticos durante un proceso creativo es la búsqueda de ideas, que aunque parecen ocurrencias personales y originales, en la mayoría de los casos esconden prejuicios y funcionan de forma coactiva. Trabajar cuestionando el poder de la "idea", permitiría que el disenso tome lugar tanto en los procesos educativos como en los políticos.

Tal y como apunta Javier Seguí (2003) en los procesos creativos la idea no es siempre la feliz solución sino es también la causa de bloqueos y frustraciones porque uno confía en ella desconfiando en la importancia del proceso como una alternancia continua de acciones y reflexiones. El proceso es algo más que permanecerse fiel a una idea del inicio.

No confiar tanto en las ideas y no deificarlas se cree que es un proyecto educativo de gran valor no sólo en los procesos creativos sino también para la democracia porque apostar por el proceso para un buen resultado hace que todos empiecen de una base común que es la igualdad de inteligencias. Creer que sólo una idea puede aportar un buen resultado y apoyar algo así en un proceso educativo puede conducirnos por una parte a agudizar las diferencias entre individuos y hacer que unos crean que son superiores al tener "ideas" con las que el conjunto se encuentra más a gusto, mientras que otros son inferiores por no tenerlas. Confiar en que existen ideas felices promueve la dimisión del esfuerzo para el aprendizaje y la pérdida del disfrute en el hacer, pensar y experimentar. Por otra parte un proceso de producción no transparente no puede servir mucho en un proceso de aprendizaje, ya que, es imposible aprender algo de alguien que simplemente tiene buenas ideas pero no desvela nada de su forma de trabajo y su manera de aprender y producir.

Morin dice sobre las ideas que "...no sólo son productos de la mente, también son seres mentales que tienen vida y poder... pueden poseernos..." y apunta que "El primer objetivo de la educación del futuro es [...] enseñar a los estudiantes convivir con sus ideas, sin ser destruidos por ellas." (Morin, 1999, p.10)

Esta reflexión de Morin nos hace pensar que las ideas no son nunca algo nuevo sino algo que está ahí y puede condicionar nuestros pensamientos y acciones. Si consideramos que el cerebro es un órgano que necesita al imentarse de conocimientos existentes para poder producir conocimientos nuevos, podemos pensar que las ideas son a menudo conocimientos, pensamientos, creencias u opiniones preexistentes que aunque pensamos poseer a menudo nos hacen comportarse como poseídos por ellas.

La contribución del aprendizaje de los procesos creativos en la conciencia política de los estudiantes.

Psegiannaki, Katerina; García Triviño, Francisco. D.O.I. 10.14198/i2.2016.5.02 
Por lo tanto una postura educativa conforme con lo anteriormente mencionado aunque no negaría las ideas existentes, o las ideas que aparecen primeras, iría frente a ellas, cuestionándolas, derrumbándolas y criticándolas constructivamente para sacar de ellas lo más positivo. Tal postura puede llegar a ser un comportamiento creativo pero también puede llegar a ser un comportamiento de conciencia política que apuesta por el progreso. Nuestras ideas, no son producto de ninguna inspiración privilegiada, sino surgen por nuestra existencia en lo sensible, por estar vinculados con otros seres humanos, por vivir en el lenguaje, por querer aprender, compartir, interpretar y producir nuevos conocimientos. Toda producción de ideas nuevas necesita de un proceso activo que representa lo que se ha llamado anteriormente desarrollo "desde dentro". Este proceso activo es el que hace parecer en el mundo lo inédito, y presupone compartir palabras y cosas es decir adoptar una actitud política y reivindicar nuestra posición de igualdad en lo sensible.

\section{El diálogo, a modo de conclusión.}

El aprendizaje de los procesos creativos y la política pueden tener una cosa muy importante en común, y eso es su apuesta hacia el cambio y su confianza en el progreso. En los dos ámbitos para que el progreso y el cambio tomen lugar hace falta concienciarse de los prejuicios y desposeerse de viejas y fijas ideas. Posiblemente la $\mathrm{m}$ anera más sencilla para que esto pueda llegar a ocurrir, sea el diálogo, el proceso educativo y político por excelencia, y una forma de comunicación que apuesta por la democracia. Ese proceso pone en evidencia la neces idad de tener un interlocutor, diferente a nosotros y que nos haga ver lo que no somos capaces de ver por nuestra cuenta siendo eso un proceso imprescindible para la praxis creativa y política. Especialmente para las carreras que implican procesos creativos sería imposible negar la importancia del diálogo como desencadenante para la reflexión, porque solamente así se podría desarrollar, junto a las habilidades prácticas, una conciencia crítica y constructiva.

La vida humana consiste en habitar un mundo en que las cosas no sólo son sino también significan, y ese significado es lo que uno no puede inventar ni sostener en aislamiento, porque simplemente depende de la mente del otro. José Luis Pardo habla de la dificultad del "logos" que consiste en la necesidad de tener que atribuir a un sujeto un predicado que no se deriva analíticamente de su concepto y va más allá de lo que la experiencia, la memoria o la costumbre nos permiten decir. Y como característicamente dice:

“...quien nos obliga ir más allá de nosotros mismos más allá del sujeto a buscar el predicado, más allá de nuestra experiencia personal o nuestra memoria colectiva es ese otro cualquiera que tenemos enfrente... que a las preguntas que nosotros hacemos responde el cualquier otro - ya habremos logrado ensanchar nuestras miras más allá del estrecho horizonte de nuestra comunidad...." (Pardo; 2004, p.425)

Elizabeth Ellsworth propone para los procesos educativos un diálogo analítico traído desde el psicoanálisis. Con el diálogo analítico la pregunta se desplaza desde el ¿qué significa algo en la realidad o en la verdad? a ¿de qué forma el mundo incrementa o decae en valor por las interpretaciones de las cosas y acontecimientos que se hacen? Bajo esta lógica el comportamiento de los integrantes de un diálogo analítico deja de ser la búsqueda de justificaciones para la actuación bajo una "lógica", una "moral" o una "ética" que determinen la verdad o la real idad y pasan a ser la necesidad, el derecho y la responsabilidad para participar en la construcción de signific ado (Ellsworth, 2007, pp.130,13). Este proceso ocurre necesariamente en ambos procesos políticos y artísticos que no quieren basarse en clichés, convenciones y prejuicios sino participar activamente en la construcción del sign ificado. Como característicamente dice Agnes Heller (1987, p.310), un artista o un científico (y nosotros añadimos un político) que en su trabajo se deje guiar por prejuicios, se halla fuera de la del dominio del arte o de la ciencia (añadimos política) aunque en la vida cotidiana consiga afirmarse muy bien.

Lo que ganamos con el diálogo analítico es "la capacidad de situar nuestros procesos de interpretación y de producción de significado en el marco de referencia que no está únicamente informado por la negación, la represión, el olvido, la ignorancia, ni tampoco por la certeza, el conocimiento y la compresión" (Ellsworth, 2005, p.136) sino en un marco que como dice Rancière interrumpe las coordenadas normales de la experiencia sensorial. Toda negación represión, olvido e ignorancia y toda certeza, conocimiento y compresión se perturban a partir del disenso que provoca una diferencia en lo sensible y un desacuerdo sobre los datos mismos de una situación. El disenso político que toma lugar a través de los procesos creativos no consiste en reparar fracturas sociales o preocuparse por individuos y grupos desechados, sino en reconstituir un espacio de división y capacidad de intervención política, poniendo de manifiesto el poder igualitario de la inteligencia (Rancière, 2005, p. 55). 


\section{Bibliografia}

ARENDT, Hannah. Entre el pasado y el futuro. Madrid: Península, 1996.

BÁRCENA, Fernando. Hannah Arendt: una filosofía de la natalidad Barcelona: Herder, 2006.

DEWEY, John. Experiencia y Educación. Madrid: Biblioteca Nueva, 2004.

DURKHEIM, Émile. Educación y sociología. Barcelona: Península, 1975.

EISNER, Eliot. Educar la visión Artística. Barcelona: Paidós Ibérica, 2009 (primera edición 1972).

ELLSWOTH, Elizabeth. Posiciones en la enseñanza. Madrid: Akal, 2005.

FERRATER MORA, José. Educación. En Diccionario de Filosofía. Buenos Aires: Editorial Sudamericana, 1965, pp. 499-500.

HELLER, Agnes. Sociología de la vida cotidiana. Barcelona: Península, 1987 (primera edición 1977).

JAY W. Roberts. Beyondlearning by doing: theoretical currents of experience ineducation, 2009. Recuperado de:

http://biblioteca.universia.net/html bura/ficha/params/title/beyond-learning-by-doing-theoretical-currents-of-experience-ineducation/id/50899709.html

LLEDÓ, Emilio. Educación e Igualdad. En Serquien eres. Ensayos para una educación democrática. Zaragoza: Prensas Universitarias de Zaragoza. Colección: [Re]pensar la educación, 2009, pp. 51-62.

MORIN, Edgar. Los siete saberes necesarios para la educación delfuturo. Paris: Unesco, 1999

PARDO, José Luis. La regla del juego, sobre la dificultadde aprender filosofía. Barcelona:Círculo de lectores, S.A., 2004.

RANCIĖRE, Jacques. Sobre políticas estéticas. Barcelona: Universitat Autónoma de Barcelona Servei de Publicacions, 2005.

RANCIÈRE, Jacques. El reparto de lo Sensible. Santiago: LOM, 2009.

READ, Herbert. Educación por el arte. Barcelona: Paidós Ibérica, 2010 (1 a edición 1986).

ROBERTS, Peri \& SUTCH, Peter. An introduction to Political Thought, A conceptual toolkit. Edinburg: Edinburg University Press, 2006.

SÁNCHEZCEREZO, Sergio. Diccionario de las ciencias de la educación, Madrid: Santillana, 1994(1983 Ed. Revisada en 1994).

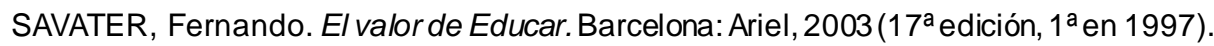

SEGUÍ, Javier. Dibujar proyectar IV. Acerca de algunas incongruencias en la enseñanza del dibujo y del proyecto arquitectónico. Madrid: Instituto Juan de Herrera, 2003.

SOTELO, Ignacio. Educación y Democracia, 1996. Recuperado de: http://biblioteca.itam.mx/estudios/estudio/letras4546/texto02/sec $1 . \mathrm{html}$

\section{Biografía}

Katerina Psegiannaki: Arquitecta por la Universidad de Tracia, Grecia, doctora arquitecta por la Universidad Politécnica de Madrid. Profesora en el Grado de Diseño Digital en la Universidad Internacional de la Rioja. Co Directora de la revista experimental HipoTesis Serie Alfabética y la revista científica HipoTesis Serie Numerada.

Tesis: Contextualización teórica del acto pedagógico en la enseñanza y el aprendizaje del proyecto arquitectón ico: el caso de la ETSAM. 2015.

Artículos relacionados:

Aprendizaje mediante contenidos no determinados en la enseñanza del proyectar arquitectónico, Arquitecturas del Sur, 33, 48,68-79,2015.

Working with Hands: Surprised with the Common, Accustomed to the Strange. The International Journal of the Arts in Society: Annual Review, Volume 7, pp.69-80. 2014

Francisco García Triviño: Arquitecto por la Universidad de Granada, doctor arquitecto por la Universidad Politécnica de Madrid. Profesor de proyectos arquitectónicos en la Universidad Camilo José Cela. Co-director de la revista experimental HipoTesis Serie Alfabética y la revista científica HipoTesis Serie Numerada.

Tesis: Atlas y topología del error como un sistema productivo en la arquitectura. 2014.

Artículos relacionados:

-Aprendizaje mediante contenidos no determinados en la enseñanza del proyectar arquitectónico, Arquitecturas del Sur, 33, 48,68-79,2015.

- Trabajar con desconocidos. ,Il Jornades sobre Innovació Docent en Arquitectura (JIDA'14), 2014. 